\title{
How to endoscopically repair a biliodigestive fistula complicating a perforated peptic ulcer: a customized "natural" choledochoduodenal anastomosis
}

A perforated peptic ulcer is associated with a $30 \%$ mortality and $50 \%$ morbidity and is usually managed as a surgical emergency [1]. To seal the perforation, applying interrupted sutures with omental apposition is the most commonly used technique [2]. In a few cases, a perforated peptic ulcer may be complicated by a choledochoduodenal fistula, which is managed surgically by laparoscopic digestive resection [3] or medically with a protein pump inhibitor and endoscopic retrograde cholangiopancreatography (ERCP). We present a case of a biliary fistula complicating a perforated peptic ulcer that was managed endoscopically in an original way.

An 84-year-old man presented with abdominal pain and fever. Clinical results showed an inflammatory syndrome associated with normal findings from hepatic tests. A perforated peptic ulcer was confirmed by computed tomography (CT) and antibiotic therapy was started (piperacillin/tazobactam $12 \mathrm{~g}$ daily). The patient had emergency surgery with suturing and abdominal drainage. The drain started producing biliary fluid 1 week

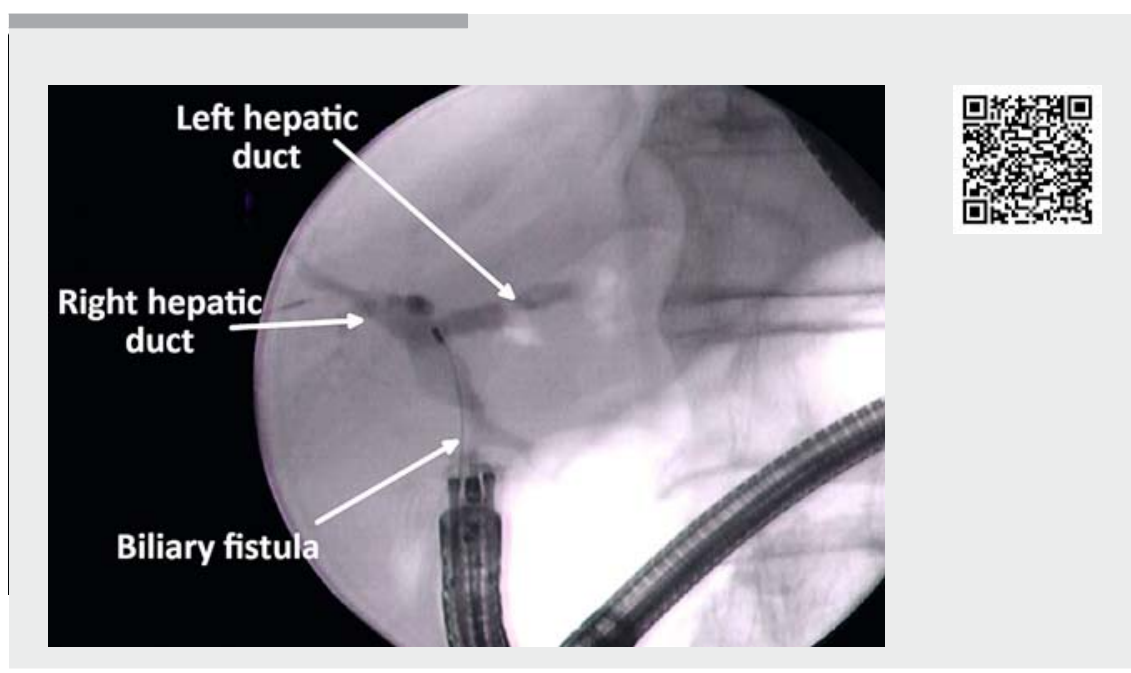

$\checkmark$ Video 1 Endoscopic repair of biliodigestive fistula complicating a perforated peptic ulcer, providing a customized "natural" choledochoduodenal anastomosis.

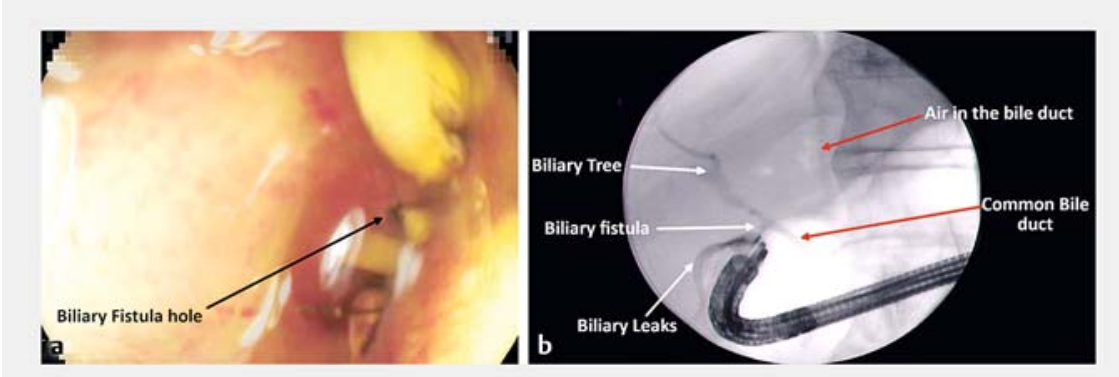

- Fig. 1 A perforated peptic ulcer complicated by a leaking choledochoduodenal fistula. a Biliary fistula opening. $\mathbf{b}$ A perforated peptic ulcer with biliary leak.

later at a volume of 300 to $500 \mathrm{~mL} /$ day. At 1 month, imaging confirmed a persistent duodenal leak, and the patient was transferred to our tertiary center.

Endoscopically, we found an ulcer located in the bulb in contact with the surgical drain hiding the choledochoduodenal fistula ( $\triangleright$ Fig. 1 a, $\triangleright$ Video 1 ). First, a straight catheter with a guidewire was introduced into the choledochoduodenal fistula and opacification allowed visualization of the biliary tree ( Fig.1b). Second, a fully covered metal biliary stent was deployed, with the proximal flange in the common bile duct and the distal flange in the stomach, to channel the biliary flow. Third, an enteral metallic fully covered stent was deployed that covered the bulb ulcer ( $\triangleright$ Fig. 2). There was no perioperative complication. At day 1 , no biliary fluid persisted in the drain, which was removed. At 6 weeks, an endoscopic control showed after stent removal a complete cicatrization of the bulb ( $\triangleright$ Fig. 3 a) with a "natural" choledo-

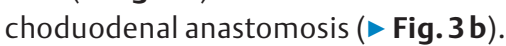
This case illustrates the possibilities of therapeutic endoscopy to treat complex biliary fistulas by directing the bile towards the digestive tract.

Endoscopy_UCTN_Code_TTT_1AR_2AG

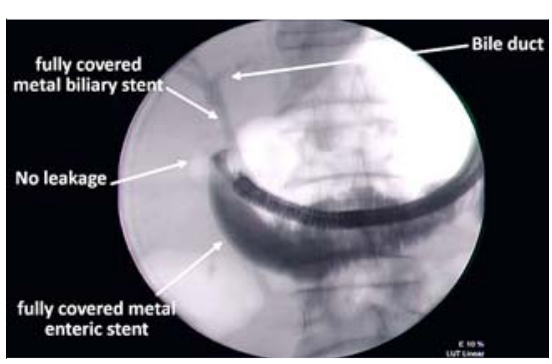

Fig. 2 Endoscopic treatment with multiple prostheses. 

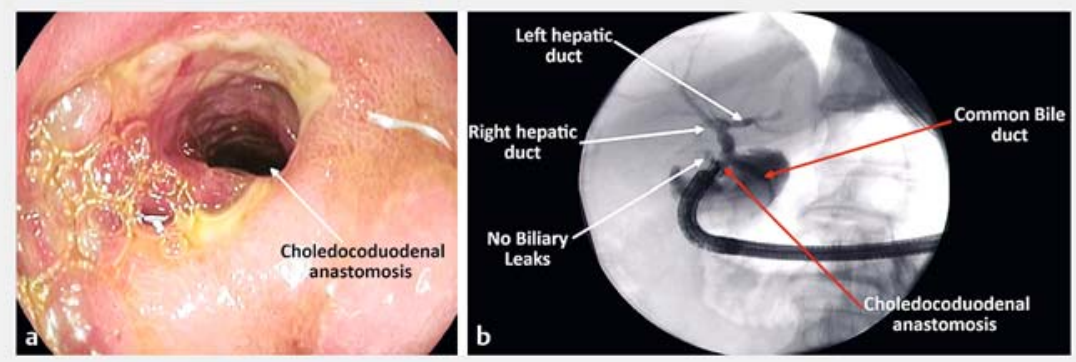

- Fig. 3 Control of endoscopic treatment at 6 weeks. a Choledochoduodenal anastomosis lumen. b Fluoroscopic control showing a customized "natural" choledochoduodenal anastomosis.

\section{Competing interests}

None

The authors

Laurent Monino'1,2, Jean-Michel Gonzalez ${ }^{2}$, Marc Barthet ${ }^{2}$

1 Department of Hepatogastroenterology, Université catholique de Louvain, Cliniques universitaires Saint-Luc, Brussels, Belgium

2 Department of Hepatogastroenterology, Assistance Publique des Hôpitaux de Marseille, Aix-Marseille Université, Hôpital Nord, Marseille, France

\section{Corresponding author}

\section{Laurent Monino, MD}

Department of Hepatogastroenterology, AP-HM, Aix-Marseille Université, Hôpital Nord, Chemin des Bourrely, 13015 Marseille, France

Fax: +33-4-91968737

laurent.monino@uclouvain.be

monino.laurent@hotmail.fr

\section{References}

[1] Møller MH, Adamsen S, Thomsen RW et al. Multicentre trial of a perioperative protocol to reduce mortality in patients with peptic ulcer perforation. Br J Surg 2011; 98: 802 810
[2] Søreide K, Thorsen K, Harrison EM et al. Perforated peptic ulcer. Lancet 2015; 386: $1288-1298$

[3] Tonolini M. Spontaneous pneumobilia revealing choledocho-duodenal fistula: A rare complication of peptic ulcer disease. J Emerg Trauma Shock 2013; 6: 146-147

\section{Bibliography}

DOI https://doi.org/10.1055/a-0978-4760

Published online: 21.8.2019

Endoscopy 2020; 52: E31-E32

(c) Georg Thieme Verlag KC

Stuttgart · New York

ISSN 0013-726X

\section{ENDOSCOPY E-VIDEOS \\ https:|/eref.thieme.de/e-videos}

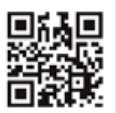

Endoscopy E-Videos is a free access online section, reporting on interesting cases and new techniques in gastroenterological endoscopy. All papers include a high quality video and all contributions are freely accessible online.

This section has its own submission website at https://mc.manuscriptcentral.com/e-videos 